\title{
FUE - A Permanent Treatment for White Hair Removal?
}

\author{
Arif Z* \\ La Densitae Clinic, India
}

\begin{abstract}
Background: There are multiple treatment modalities for white hair removal but the results are non-satisfactory for the patients as well as the practitioners. Follicle Unit Extraction can be used as a onetime and permanent option for the removal of unwanted white hair.
\end{abstract}

Methods: White beard removal was done from 3 patients using FUE technique under aseptic conditions.

Results: A complete removal of unwanted white hair was seen in all the patients. Follow up was done for 4 months and there was no case of re-growth.

Conclusion: Within the limitation of the small number of patients, it can be concluded that FUE can be considered a permanent and one-time treatment for the removal of unwanted white hair.

Keywords: White hair, Transacted hairs, Regrow

\section{Introduction}

Leukotrichia or white hair usually occurs due the absence of melanin in the hair follicle. It can develop at any hair covered areas of the body. The most common sites are the scalp, beard and neck. It is a common problem for both genders. A number of treatment modalities have been tried but the results are dissatisfactory. The most common treatment offered is laser hair removal but it is found to be less effective. If there is a mixture of white and black hair in the area of the body then exclusive removal of white hair with the help of laser is impossible. Follice unit Extraction has been used in hair transplant surgery since a long time and can be applied to the other hair bearing areas of the body as well for the permanent removal of unwanted white hair.

\section{Objectives}

To evaluate if FUE is a permanent and one-time treatment option for white hair removal.

\section{Material and Methods}

We conducted this study on 3 patients who came with the complaint of unnecessary white beard and wanted removal for the same. A thorough clinical examination was done. Patients were explained all the treatment options. A well informed written consent was taken. FUE (follicle unit extraction) was performed under local anaesthesia.

Beard was trimmed to 0.5 to $1 \mathrm{~mm}$. Under aseptic conditions, local anaesthesia was administered in the desired area. After the desired anaesthesia was achieved, FUE was performed using a motorized punch holder under magnification. $0.7 \mathrm{~mm}$ sharp serrated punches were used for the same. Special care was taken to avoid any kind of transection of the follicles as transacted follicles tend to regrow. The extracted follicular units were examined under magnification. Dressing was done and the patients were recalled for review after 2 days, 10days, 1 month and 4 months.

\begin{tabular}{|l|l|}
\hline Quick Response Code: & FCorresponding author: Zeeshan Arif, La Densitae Clinic, Kochi, India \\
Received: 31 May, 2021 & Published: 06 July, 2021 \\
\hline
\end{tabular}




\section{Results}

The present study was conducted only in men and FUE was done only for the beard white hair. A complete extraction of the follicle units was achieved in all the patients. There was no regrowth of the white hair after a follow up of 4 months. There was no scarring present in the treated areas. The patients were overwhelmed and fully satisfied with the results achieved (Figure 1).

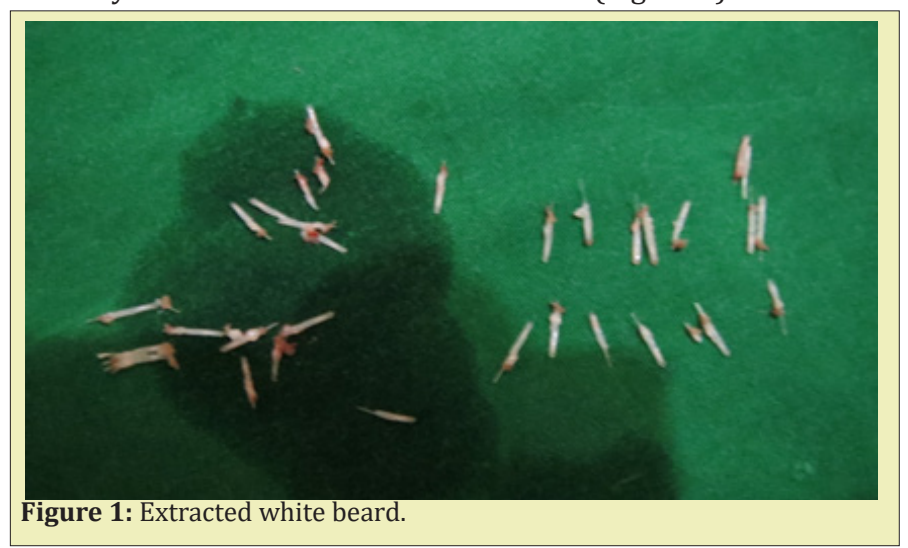

\section{Conclusion}

Our study concludes that FUE is an effective and permanent treatment for the removal of white hair. Many light- and heat-based therapies have been tried for white hair removal such as use of radiofrequency, ${ }^{1}$ laser after colouring ${ }^{2}$ or use of melanin encapsulated liposomes ${ }^{3}$ before laser therapy. However, none of them have proven to be an effective therapy with results varying from $17 \%-54 \%{ }^{4}$

Electrolysis is considered to be the treatment of choice for white hair removal. ${ }^{5}$ But it is a very tedious procedure requiring multiple sitting for the treatment. Complications like folliculitis, regrowth post-inflammation hyperpigmentation and scarring can occur. ${ }^{4}$

If the extent of white hair is more, the rate of transection can be more. These transacted hairs tend to regrow. In these cases 2 or 3 sittings of FUE might be required. If the white hair area to be removed is lesser FUE can be considered as a onetime and permanent treatment option.
FUE can be used for the treatment of leukotrichia effectively. It can provide a permanent solution for unwanted white hair of the body. With experience, one can extract up to 2000 follicles in an hour which is much faster than any other option available for white hairs. ${ }^{4}$

\section{Shortcomings of the Study}

A larger study population can be included in further studies including various skin types and different body parts. FUE should be performed by highly skilled professionals under adequate magnification as transection will lead to regrowth of hair. Very fine $(0.7$ to $0.75 \mathrm{~mm}$ ) sharp serrated punches should be used to avoid any kind of scarring.

\section{Acknowledgments \\ None.}

\section{Funding}

None.

\section{Conflicts of Interest}

Author declares that there is no conflict of interest.

\section{References}

1. Sadick NS, Laughlin SA. Effective epilation of white and blond hair using combined radiofrequency and optical energy. J Cosmet Laser Ther. 2004;6:27-31.

2. Alijanpoor R, Poorsattar Bejeh Mir A, Mokmeli S. Successful white hair removal with combined coloring and intense pulsed light (IPL): A randomized clinical trial. Photomed Laser Surg. 2011;29:773-779.

3. Sand M, Bechara FG, Sand D, Altmeyer P, Hoffmann K. A randomized, controlled, doubleblind study evaluating melaninencapsulated liposomes as a chromophore for laser hair removal of blond, white, and gray hair. Ann Plast Surg. 2007;58:551-554.

4. Gupta J, Chouhan K, Kumar A. White hair removal with follicle unit extraction. Journal of Cutaneous and Aesthetic Surgery. 2016;9(3):209210.

5. Richards RN, Meharg GE. Electrolysis: Observations from 13 years and 140,000 hours of experience. J Am Acad Dermatol. 1995;33(4):662666. 